\title{
REATIVAÇÃO DE PALEOLINEAMENTOS DURANTE A EVOLUÇÃO DA BACIA DO PARANÁ - O EXEMPLO DO ALTO ESTRUTURAL DE QUATIGUÁ
}

\author{
SIDNEI PIRES ROSTIROLLA ${ }^{1}$, MARIO LUIS ASSINE ${ }^{2}$, LUIZ ALBERTO FERNANDES ${ }^{1}$ \& PAULO CÉSAR ARTUR ${ }^{1}$
}

\begin{abstract}
PALEOLINEAMENT REACTIVATION DURING THE PARANÁ BASIN EVOLUTION - THE EXAMPLE OF THE QUATIGUÁ STRUCTURAL HIGH This paper discusses the tectonic controls in the evolution of the Quatiguá Structural High, Paraná Basin, Brazil. The study was based on field mapping and descriptive-kinematic structural analysis of faults, brittle shear zones, tilted strata and joint systems, which are post-depositional in relation to the outcropping sedimentary section. The Quatiguá high is a domic structure that affects palaeozoic rocks of the Paraná Basin. It presents circular geometry in map and is part of a regional positive-flower-structure, associated to NE basement faults, which is transected by superimposed NW faults. In the center of the domic structure outcrops the Itarare Group, which is successively surrounded by Guata and Passa Dois groups, all of them intruded by basic intrusive rocks related to the Juro-Cretaceous Serra Geral basalt flooding event. The lithostratigraphic units show a concentric disposition, in which the beds dip gently away from the center in all directions. The final geometry has resulted from a combination of left-lateral NE wrench faults, evolved during Permian-Triassic limit, and NW extensional faults to rightlateral NE transtensional faults during Mesozoic. The basic magmatism was probably related to this second deformation event. The observed relations permitted the construction of a preliminary petroleum trap model, which can be used as a prospective guide in deeper zones in the basin.
\end{abstract}

Keywords:

RESUMO Neste trabalho são discutidos os controles na evolução tectônica do Alto Estrutural de Quatiguá, Bacia do Paraná, Brasil. O estudo foi baseado em mapeamento regional e análise estrutural descritiva e cinemática de falhas, zonas de cisalhamento rúpteis, basculamento de camadas e sistemas de juntas, que constituem estruturas pós-deposicionais à seção sedimentar aflorante. O Alto de Quatiguá é uma estrutura dômica, com forma circular em mapa, que afeta rochas paleozóicas da Bacia do Paraná. Está inserido numa estrutura-em-flor positiva com orientação NE, condicionada por falhas presentes no embasamento e posteriormente seccionada por falhas NW. No centro da estrutura dômica afloram rochas do Grupo Itararé, contornadas sucessivamente por litotipos dos grupos Guatá e Passa Dois, sendo que em vários níveis estratigráficos ocorrem intrusões básicas associadas ao vulcanismo Serra Geral. As camadas mostram disposição concêntrica, com mergulhos para fora da estrutura. A geometria final resultou da combinação de transcorrência sinistral NE durante o limite Permiano-Triássico, e de deformação distensional segundo NW e transtensional dextral ęn falhas NE no Mesozóico. O magmatismo básico esteve, provavelmente, relacionado ao segundo evento deformativo. As relações estratigráfico-estruturais observadas em campo permitiram a elaboração de um modelo preliminar de formação de armadilhas para petrơleo, que pode ser utilizado como guia prospectivo em zonas mais profundas na bacia.

Palavras-chaves: Herança tectônica, bacias intracratônica, exploração de petróleo.

\section{INTRODUÇÃO}

A reativação de estruturas herdadas do embasamento é um fenômeno de ocorrência relativamente comum em bacias intracratônicas. A análise destas estruturas, em suas várias fases de atividade, tem papel fundamental no entendimento da evolução tectônica e sedimentar de áreas cratônicas, auxiliando na solução de problemas que envolvem a reconstrução paleogeográfica e a determinação de locais mais propícios para descobertas de novos campos de petróleo. Na Bacia do Paraná, em cujo embasamento existem cicatrizes de eventos pré-cambrianos, a ação de tensões sobre uma placa heterogênea reativou falhas e gerou uma série de feiç̧̃es tectônicas, algumas das quais desempenharam papel controlador e modificador de sua seção sedimentar.

O presente trabalho discute a evolução tectônica do Alto Estrutural de Quatiguá, que representa uma das feições originadas e modificadas pela reativação de falhas do embasamento. O objetivo principal do estudo compreende a caracterização tectônica do alto estrutural mencionado, localizado no nordeste do estado do Paraná (Fig.1) e informalmente também denominado Domo de Quatiguá.

O reconhecimento de morfoestruturas dômicas tem sido objeto de investigação na Bacia do Paraná desde os anos 60/70, principalmente através de trabalhos de campo (Andrade \& Soares 1970, 1971, Soares 1974) e análise morfoestrutural com base em fotos aéreas e imagens de satélite e radar (Soares et al. 1982). Muitas feições dômicas já foram mapeadas nas faixas de afloramentos da bacia, havendo possivelmente outras sob a cobertura dos derrames basálticos da Formação Serra Geral. Diferentes métodos já foram empregados para o mapeamento de tais estruturas, que estão localizadas ao longo de grandes Iineamentos gerados pela reativação de falhas do embasamento, sob a cobertura sedimentar. A importância da herança tectônica na evolução da bacia já foi destacada por diversos autores, com diferentes interpretações quanto à gênese das reativações, tais como movimentos verticais de blocos e associação com flexão da placa ou rifteamento durante a fase inicial de subsidência (e.g. Ramos 1970, Soares 1974, Almeida 1980, Fúlfaro et al. 1982, Cordani et al. 1984, Brito Neves et al. 1984), ou ainda movimentos horizontais como reflexo de tensões induzidas pelas deformações nas bordas das placas (e.g. Soares 1991, Zalán et al.
1987,1990). Milani (1997) fez referência a movimentos verticais, com a origem da bacia tendo sido influenciada por riftes na fase inicial, porém com deformaçōes relacionadas a movimentos horizontais recorrentes nas fases posteriores.

No caso do Alto de Quatiguá, resultados de levantamentos de campo em escala regional e de semi-detalhe foram apresentados por Nogueira Filho (1988), Soares (1991), Ferreira et al. (1996), Soares et al. (1996), Rostirolla et al. (1999), entre outros. Programas de mapeamento de detalhe foram também desenvolvidos, visando entender os controles estruturais e litológicos em prospectos para petróleo (Vieira \& Maingué 1972) e para urânio (Nagalli 1977). Mesmo com os avanços em termos do reconhecimento geológico da área, poucos foram os trabalhos que enfatizaram aspectos tectônicos relativos à gênese do Alto de Quatiguá, exceção devendo ser feita aos trabalhos de Soares (1991) e Nogueira Filho (1988), que no entanto centraram os estudos na análise da tectônica sin-sedimentar. O presente trabalho pretende dar uma contribuição adicional no tocante ao entendimento dos controles tectônicos na evolução do Alto de Quatiguá, com a reavaliação dos trabalhos de mapeamento regional já apresentados.

São enfatizados os aspectos pós-deposicionais da formação do alto estrutural, com base nos quais tenta-se explicar o condicionamento da feição dômica à reativação de descontinuidades litosféricas herdadas do embasamento. Alguns aspectos da estratigrafia e tectônica sindeposicional também são apresentados, com o intuito de efetuar a conexão entre as várias fases evolutivas registradas na área do Alto de Quatiguá. Adicionalmente, são apresentados alguns modelos de formação de armadilhas para petróleo, concebidos a partir do estudo da área e aplicáveis a situações tectônicas semelhantes em outros locais na Bacia do Paraná.

Para este trabalho foi utilizada uma síntese de mapeamentos geológicos em semi-detalhe desenvolvidos na Universidade Federal do Paraná, nos últimos 5 anos, que deram suporte à avaliação dos controles tectônicos do Alto Estrutural de Quatiguá. Para complementação e integração de dados foi efetuada nova interpretação de fotos aéreas 1:60.000 (USAF 1963) e imagem de satélite Landsat TM, visando caracterizar os principais lineamentos, rupturas de relevo e feições geomórficas, além de estudos de maior detalhe em alguns afloramentos-chave na área.

1 Universidade Federal do Paraná, Departamento de Geologia, Centro Politécnico, Curitiba - Paraná - CEP: 81.531-990. E-mails: sidnei@geologia.ufpr.br, fernande@geologia.ufpr.br; pcartur@zaz.com.br

2 Departamento de Geologia Aplicada, Universidade Estadual Paulista, Campus de Rio Claro, Av. 24-A, 1515 - Rio Claro - SP. E-mail: assine@ @rc.unesp.br 


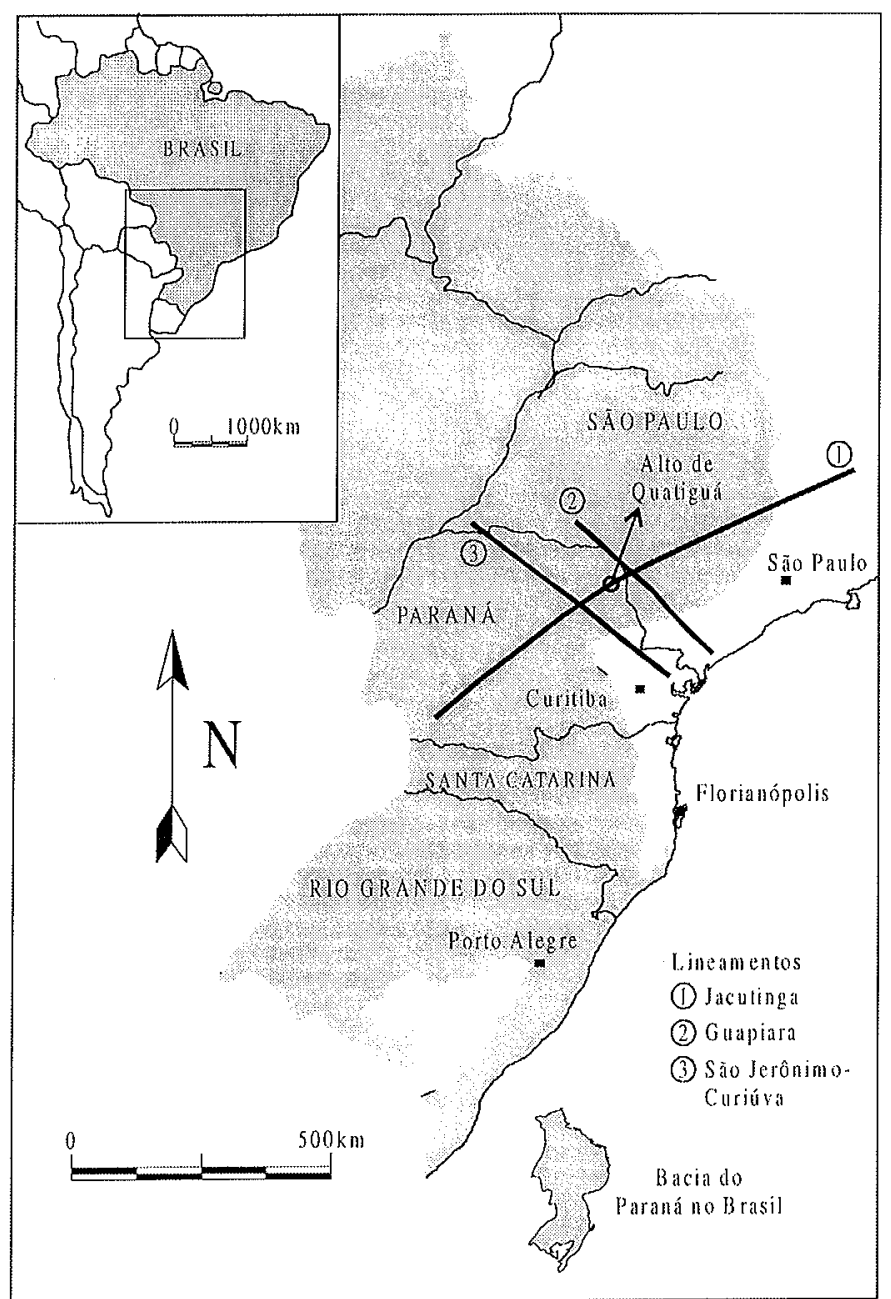

Figura 1 - Mapa de localização do Alto Estrutural de Quatiguá.

A configuração atual do Alto de Quatiguá corresponde ao efeito cumulativo de eventos tectônicos que ocorreram a partir do Neopermiano. Na região, estão registradas algumas das mudanças tectono-estratigráficas mais importantes que afetaram a Bacia do Paraná, o que torna o Alto de Quatiguá um importante alvo para a pesquisa sobre a evolução geológica da bacia, bem como para a geração de modelos para potenciais acumulações de petróleo. Não obstante o arcabouço estrutural observado seja decorrente de uma evolução policíclica, alguns aspectos simples, que serviram como ponto de partida do presente estudo, devem ser ressaltados:

1 a forma dômica atual;

2 a estrutura localiza-se sobre a zona de falha Pitanga-QuatiguáJacutinga (Soares et al. 1996) de direção NE, em região próxima ao cruzamento desta com o Alinhamento de Guapiara (Ferreira 1982), de direção NW;

3 a feição dômica é circundada por diversos córpos ígneos (diques, soleiras e lacólitos), de idade juro-cretácea, com vários pontos de magmatismo situados em cruzamentos de falhas NE e NW;

4 a maioria dos indicadores cinemáticos encontrados sugerem uma deformação mista: transpressional anterior ao magmatismo e transtensional durante e/ou após o magmatismo;

5 há registro de pelo menos dois eventos de tectônica modificadora, distintos e recorrentes;

6 o alto estrutural é posterior às unidades paleozóicas aflorantes, uma vez que estas estão estruturadas por ele.

CONTEXTo Geológico A Bacia do Paraná A Bacia do Paraná é uma depressão alongada na direção NNE-SSW, com área de aproximadamente $1.600 .000 \mathrm{~km}^{2}$, abrangendo parte do Brasil, Paraguai, Argentina e Uruguai. Seu preenchimento sedimentar compreende cinco grandes unidades estratigráficas, que perfazem um total de aproximadamente 6.000 metros de espessura. É uma bacia cratônica flexural, de evolução policíclica, com início da deposição no Ordoviciano, aparentemente sem um rifte precursor (Zalán et al. 1990, Soares 1991). O registro tectono-estratigráfico conhecido sugere que os fenômenos orogênicos das bordas da Placa Sul-Americana influenciaram os eventos epirogênicos intraplaca, correspondentes a épocas de subsidência, soerguimento e magmatismo. Os diversos embaciamentos formados ao longo do tempo, que se intercalaram a períodos de soerguimento e perda do registro sedimentar, levaram Zalán et al. (1990) a sugerir que a Bacia do Paraná corresponde à superposição de várias bacias sobre a mesma placa. No presente estudo, a Bacia do Paraná é considerada uma única bacia, embora tenha sido submetida a perturbações de origem variada, que incluem: 1) movimentações verticais típicas de áreas cratônicas extensas, em toda a sua evolução; 2) subsidência flexural modificada pela propagação de tensões horizontais a partir das margens da placa durante o Paleozóico (Zalán et al. 1990); 3) superposição de um evento de estiramento litosférico e underplating, extremamente importante na configuração geométrica final da bacia, relacionado à abertura do Oceano Atlântico Sul (White \& McKenzie 1989) no Mesozóico; e 4) fenômenos de incursão e recuo de mares epicontinentais, associados às variações climáticas e dinâmica global, que afetaram o continente Gondwana (Soares et al. 1978).

As rochas da bacia são essencialmente siliciclásticas, constituindo unidades geradas durante o Palcozóico e Mesozóico, além de ocorrências subordinadas de rochas carbonáticas, formadas durante o Permiano. As unidades maiores já receberam status de sequências conforme o conceito de Sloss (1963, in Soares et al. 1978, Soares 1991), grupos e formações (Schneider et al. 1964 e Milani et al. 1994) e sequências conforme o conceito de Vail et al. (1977, in Milani 1997).

Geologia da Área A região do Alto Estrutural de Quatiguá compreende rochas da sequência Delta de Soares et al. (1978), também referida como Permo-Carbonífera (Zalán et al. 1990) ou Gondwana I (Milani 1997), que engloba os grupos Itararé, Guatá e Passa Dois. A área estudada insere-se numa faixa de afloramentos com direção nordeste, que se estende de Joaquim Távora a Curiúva, no Estado do Paraná. A geologia da região é conhecida com razoável detalhe em virtude de levantamentos específicos para prospecção de carvão, sintetizados em Soares \& Cava (1982) e Cava (1985). Mapeamentos na escala 1:25.000, desenvolvidos sob supervisão dos autores desses trabalho, permitiram identificar os grandes conjuntos litológicos que já haviam sido mapeados, porém com reconhecimento mais detalhado de estruturas tectônicas, como falhas, blocos estruturais e sistemas de juntas.

A seção aflorante constitui parte de um ciclo transgressivo-regressivo de $2^{\text {i }}$ ordem, com interposição de eventos transgressivo-regressivos de $3^{a}$ e $4^{a}$ ordens. Na base ocorrem diamictitos, arenitos e folhelhos da Formação Taciba, cuja origem é associada ao degelo e ressedimentação marinha em ambiente periglacial. Na parte média conglomerados, arenitos e siltitos da Formação Rio Bonito, depositados inicialmente em ambiente deltaico dominado por rios e, posteriormente, em ambientes costeiros/marinhos dominados por ondas e marés. A superfície de inundação máxima encontra-se nos lamitos da Formação Palermo. Sobre estes ocorrem folhelhos escuros, margas e calcários da Formação Irati, que são sucedidos por folhelhos carbonáticos, siltitos, arenitos finos, bancos de calcários e níveis de coquinas das formações Serra Alta, Teresina e Rio do Rasto, que constituem a parte regressiva do ciclo.

A estrutura dômica é evidenciada pela disposição concêntrica das unidades, onde rochas do Grupo Itararé afloram no núcleo, contornadas sucessivamente por litotipos dos grupos Guatá e Passa Dois (Fig.2). As camadas mergulham para fora da estrutura, configurando uma geometria arqueada levemente assimétrica, com tendência maior dos mergulhos para N e NW. A disposição das unidades, em mapa, tem nítido controle estrutural, onde são registrados efeitos de movimentos verticais e horizontais ocorridos ao longo de falhas que circundam o alto central, com ocorrência extensiva de diques, soleiras e lacólitos de diabásio, de idade eo-cretáceo.

Segundo Soares (1991), durante o Carbonífero e início do Permiano, ocorreram reativações em depocentros alongados de direção 

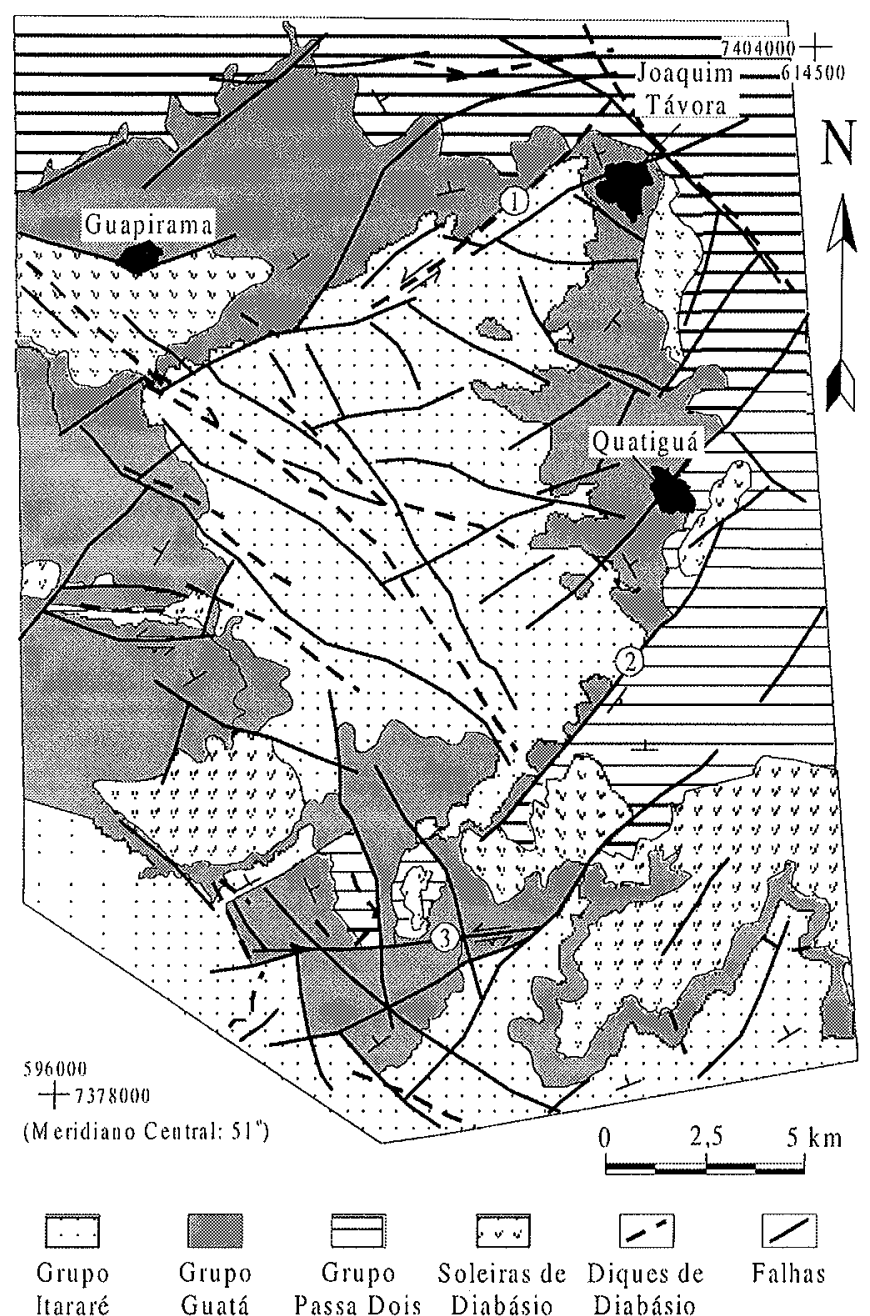
(1) F. Joaquim Távora
(2) F. Quatiguá
(3) F. Siqueira Campos
Atitudes: YCamada
GFalha Normal
$\leftrightharpoons$ Falha Transpressiva

Figura 2 - Mapa geológico simplificado do Alto de Quatiguá.

NE, de caráter transcorrente lateral direito, que controlaram a deposição dos grupos Itararé e Guatá. Este autor afirma que o caráter antigo da "estruturação Pitanga", referente à deformação ao longo da Zona de Falha de Jacutinga, é revelado pelo gradiente de variação das espessuras sedimentares. No seu modelo, a zona de falha de Jacutinga (Faixa PT3) seria a mais anômala, indicando atividade mais intensa. Embora anterior ao desenvolvimento tanto da estrutura positiva regional e da conformação dômica, Soares (1991) e Soares \& Cava (1982) sugerem que este evento controlou a deposição das associações faciológicas.

Arcabouço Estrutural Regional Vários pesquisadores (e.g. Soares et al. 1982, Zalán et al. 1987,1990, Oliveira 1991, Soares et al. 1996), interpretaram movimentos transcorrentes no embasamento da bacia como causadores de altos estruturais nas seqüências fanerozóicas, ressaltando que a movimentação de falhas antigas é um processo fundamental na determinação do arranjo geométrico e padrão de deformação da Bacia do Paraná.

Dentre as várias falhas do embasamento pré-cambriano/ eopaleozóico que se prolongam por sob a cobertura fanerozóica da Bacia do Paraná, a falha de Jacutinga (PT3) é uma das mais importantes. Esta estrutura constitui um divisor geotectônico importante, separando os terrenos do Maciço de Guaxupé e Faixa Brasília, a norte, das rochas proterozóicas das faixas Ribeira (Apiaí/São Roque) e Dom Feliciano, a sul (Cordani et al. 1984). Apresenta-se como uma feição aproximadamente contínua e estreita, caracterizada nas porções nordeste do estado de São Paulo e sudoeste de Minas Gerais, por uma foliação milonítica com orientação uniforme em torno da direção $\mathrm{E}$ NE e mergulhos fortes a moderados, em geral para NW (Campanha et al. 1983). Soares (1991) e Soares et al. (1996) interpretaram a zona de falha de Jacutinga como uma faixa estrutural de escala litosférica (Fig. 3).

Na Bacia do Paraná, o reflexo da Zona de Falha de Jacutinga corresponde a um conjunto alinhado de falhas em feixe ou localmente "en echelon", configurando uma faixa de cerca de $15 \mathrm{~km}$ de largu$\mathrm{ra}$, onde alternam-se altos e baixos alinhados a N50-60E (Soares et al. 1996). Dentro desta faixa, existem várias falhas mestras (como as falhas de Joaquim Távora e Quatiguá, Fig.2), que apresentam ângulos invariavelmente altos, rejeitos horizontais da ordem de centenas de metros a poucos quilômetros e verticais que não excedem duas centenas de metros.

Posicionado ao longo da zona de falha de Jacutinga, o Alto Estrutural de Quatiguá corresponde a uma estrutura complexa, resultante de eventos deformacionais que afetaram as unidades carboníferopermianas. Apresenta forma aproximadamente circular em mapa, configurando um alto estrutural com exposição de rochas sucessivamente mais jovens do centro para as bordas (Fig.2). Quanto à geomorfologia, o núcleo consiste em região topograficamente mais baixa, circundada por escarpas com faces voltadas para o centro da estrutura.

Magmatismo Associado Na porção central e circundando todo o alto estrutural, ocorrem corpos de diabásio na forma de diques com direções variadas (predominando N40-50W e N50-60E); soleiras e lacólitos (Fig.2). Tais rochas ainda não foram datadas, no entanto as

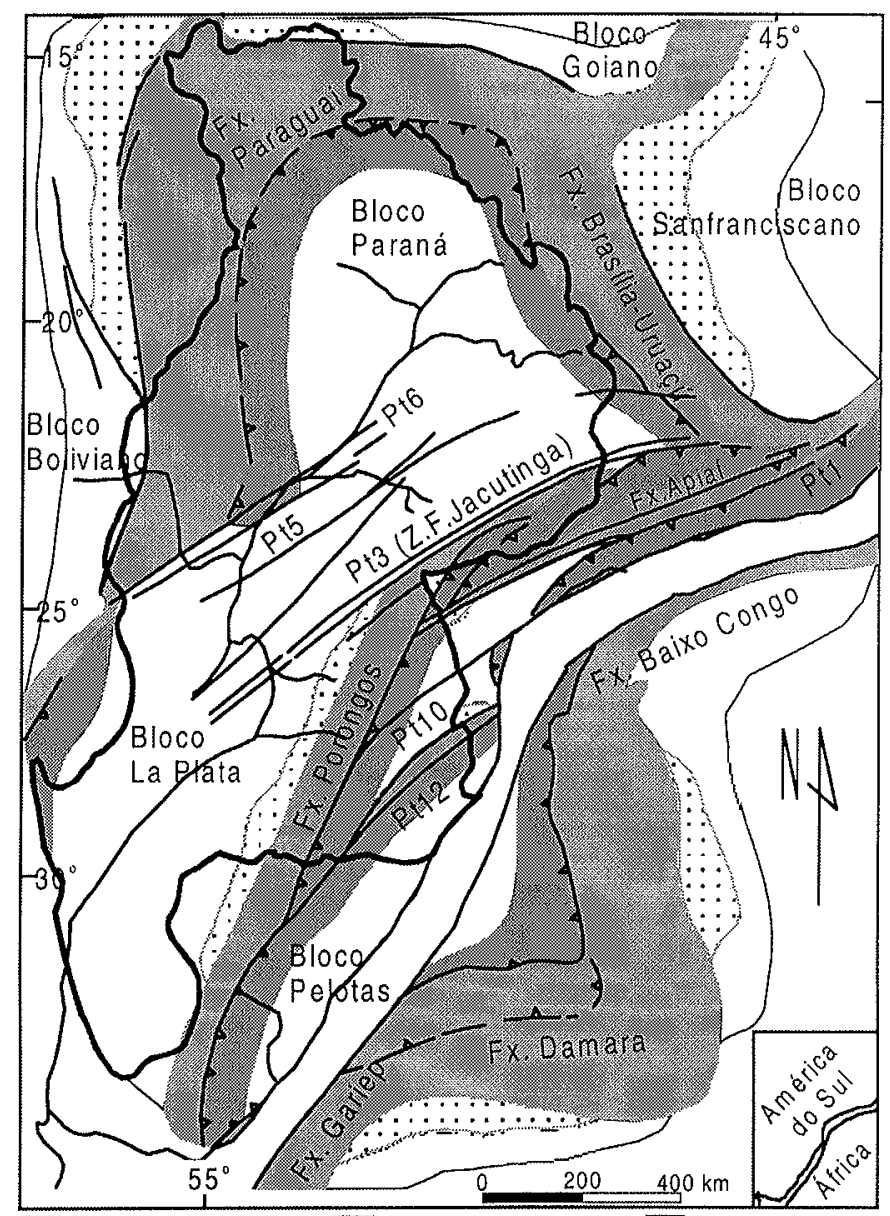

Arcos magmáticos $\square$ Bacias molássicas $\square$ Bl.cratônicos - Faixas metamórficas [Pt]Faixas Estruturais $\triangle B$. Paraná $\triangle$ Falhas $\triangle$ Zona de sutura

Figura 3 - Mapa estrutural do embasamento da Bacia do Paraná, mostrando a compartimentação geotectônica e a localização da Zona de Falha de Jacutinga (modificado de Soares 1991). 
semelhanças petrográficas permitem associá-las ao magmatismo Serra Geral. Predominam diabásios semelhantes àqueles dos diques do Alinhamento de Guapiara (Ferreira 1982), os quais possuem datação $\mathrm{K}$-Ar média de $132 \pm 10 \mathrm{Ma}$ (variando entre 114 a $144 \mathrm{Ma}$; Piccirillo et al. 1990) e, portanto, idades muito próximas das vulcânicas que predominam na Bacia do Paraná (média de $131 \pm 9 \mathrm{Ma}$, variando entre 112 a $155 \mathrm{Ma}$, Rocha-Campos et al. 1988).

A Formação Serra Geral é produto de um dos mais importantes eventos de magmatismo basáltico ocorridos no planeta, cobrindo cerca de $1.200 .00 \mathrm{~km}^{2}$, ou ainda, em torno de $75 \%$ de toda a área da bacia (Melfi et al. 1988). O evento foi responsável pela intrusão de diques e soleiras que ocorrem em vários níveis estratigráficos. O Alto Estrutural de Quatiguá encontra-se no extremo nordeste dos enxames de diques associados ao Arco de Ponta Grossa, entre os alinhamentos de Guapiara e São Jerônimo-Curiúva (Ferreira 1982), tendo se desenvolvido pouco a sul do primeiro.

O magmatismo eo-cretáceo da Bacia do Paraná foi gerado na época de abertura do Oceano Atlântico Sul, controlado pela fusão parcial ocorrida sobre uma pluma mantélica durante a divergência das placas Sul-Americana e Africana (White \& McKenzie 1989). A anomalia termal, ocasionada pelos efeitos do estiramento litosférico e da ascensão da pluma, condicionaram atividade ígnea distensional, gerando um volume expressivo de basaltos toléticos, subordinadamente andesitos, dacitos e riodacitos. De acordo com Piccirillo et al. (1990), as similaridades petrológicas, as relações isotópicas e as idades entre os diques e as vulcânicas da parte norte da bacia indicam que os primeiros foram cristalizados ao longo dos condutos dos derrames. Da mesma forma, é provável que o magmatismo presente no Alto de Quatiguá tenha se originado durante a alimentação dos derrames. O fluxo teria aproveitado tanto as estruturas mesozóicas como as anteriores, o que explica a ocorrência de diques, tanto ao longo das fraturas NW como NE. Nesta fase, as tensões geradas pela movimentação das placas condicionaram o último evento importante de deformação registrado na área, que teve deslocamentos verticais de blocos, associados a mo vimentos sinistrais nas falhas NW e à reativação dextral das falhas NE.

ANÁLISE ESTRUTURAL Análise Descritiva Na área de estudo estão registrados dois eventos deformacionais pósdeposicionais, cujas estruturas geradas compõem o principal arcabouço estrutural aflorante. As características observadas indicam deformação em regime rúptil, situada em níveis crustais superiores, situação que não favorece a geração de bons indicadores cinemáticos. Sua manifestação é evidenciada principalmente por estruturas descontínuas - sistemas de juntas e falhas - e por variações de atitudes de camadas.

Diversas famílias de juntas são observadas s:a área, localmente ocorrendo em pares conjugados, como juntas plumosas ou como superfícies lisas sem aparente feição no plano de ruptura. Localmente, as juntas são preenchidas por material esbranquiçado, constituindo carbonatos ou fragmentos de rochas. Em vários pontos são escalonadas ou com formas lenticulares que se interceptam ao longo de zonas de fraturamento mais intenso. Apresentam-se com ângulos de mergulho normalmente maiores do que $70^{\circ}$, predominando os subverticais.

A multiplicidade das direções observadas não permite, na maior parte da área, separar os sistemas de juntas em eventos distintos. Entretanto, a análise dos diagramas de dados obtidos nas bordas do alto estrutural indica que a distribuição espacial das várias famílias de juntas segue grosso modo a disposição das falhas maiores mapeadas, tendenclo aos quadrantes NE (modas N10-20E, N50-90E) e NW (moda N30-50W), localmente NS (Fig.4). Convém lembrar que os sistemas de juntas correspondem a estruturas de $2^{a}$ ordem de falhas maiores e são decorrentes de eventos rúpteis superpostos, o que dificulta a análise cinemática.

As maiores falhas mapeadas na área (Fig.2) apresentam-se como grandes fotolineamentos, marcados por rupturas de relevo, ou como faixas concentradas de fraturas, ao longo das quais ocorre deslocamento de camadas ou há indicadores de cisalhamento. Os fotolineamentos foram extraídos de fotos aéreas 1:60.000 e confrontados com falhas verificadas em campo. Dentre os vários fotolineamentos que representam fallhas comprovadas, estatisticamente os mais frequentes apresentam direção N40-60E e N40-70W (Fig.5a). A observação em campo de brechas de falha e cataciasitos não coesivos, onde lineaçōes "a" e feições lenticulares evidenciam fluxo cataclástico, permite definir que estas falhas associam-se ao sistema NE, transcorrente anti-horário. Em

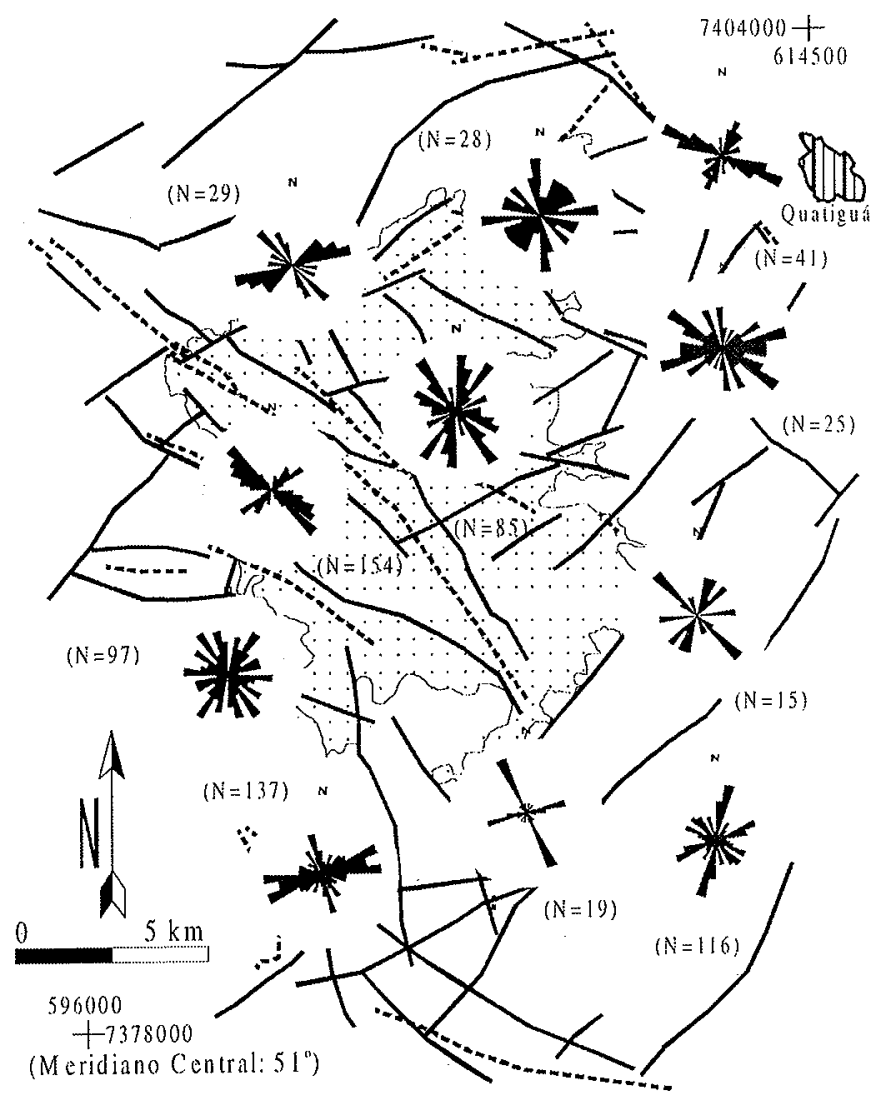

Figura 4 - Diagramas de sistemas de juntas ao redor do Alto de Quatiguá (N = numero de medidas).

levantamentos de detalhe, puderam ser observadas algumas falhas de direção NE, que mostram deformação intensa, contendo indicadores de movimento anti-horário (Fig.5b), as quais foram posteriormente preenchidas por diques de diabásio não deformados. Ao longo de direções NE e, principalmente, NW observam-se falhamentos que afetam os diques de diabásio, que apresentam cinemática diferenciada, horária em falhas NE e anti-horária em direções NW (Fig.5c).

Formas sigmóides encontradas ao longo de superfícies com frag mentação mecânica e concentração de movimentos (Fig.6a) mostram a geração de fraturas "P" que tangenciam a direção principal " $\mathrm{Y}$ ". Em termos geométricos, tais sigmóides são semelhantes àqueles encontrados em zonas de cisalhamento com hidrotermalismo e alguma recristalização, embora na área em estudo o fluxo possa ser explicado apenas por fragmentação mecânica em regime rúptil. Outras relações entre fraturas escalonadas tipo "riedel/anti-riedel" e a direção principal "Y" também indicam a mesma cinemática em falhas NE (Fig.6b)

A complexidade estrutural pode ser explicada pelo fato do Alto de Quatiguá localizar-se no cruzamento de duas grandes famílias de falhas, claramente indicadas no diagrama de fotolineamentos (Fig.5a) e no mapa geológico, correspondentes às direções Pitanga e Ivaí/Médio Piquiri de Soares et al. (1982). A deformação condicionada às falhas NE originou um alto central limitado pelas falhas de Joaquim Távora, Quatiguá e Siqueira Campos (Fig.2). O alto foi interceptado por fallhas menores de direção NW, cujo principal registro limita-se a um feixe de diques que o cruza em toda sua extensão. Este cruzamento condicionou a imposição de mergulhos centrífugos de camadas, dando uma falsa impressão de feição dômica ao alto estrutural, que na verdade corresponde a um horst NE seccionado por falhas NW. A compartimentação final dos blocos pode ter sido influenciada também pelas intrusões forçadas de alguns corpos de diabásio, principalmente lacólitos, e por rotações localizadas em falhas NW e NE.

Para a investigação da compartimentação estrutural no embasamento e de sua associação espacial com algumas das estruturas reconhecidas em superfície, foi confeccionado um mapa gravimétrico a partir de 5236 valores de anomalia Bouguer (fig.7a). Os dados apresentam-se regularmente distribuídos numa área ocupada parcialmente 
pelo estado do Paraná, centro-norte de Santa Catarina e centro-sul de São Paulo, a qual inclui a região do Alto de Quatiguá. A escolha de uma área com tais dimensões permitiu caracterizar descontinuidades regionais no relevo gravimétrico, que conforme as prerrogativas de Mantovani et al. (1989) e Quintas (1995), marcariam a justaposição de blocos do embasamento da bacia, com propriedades litológicas e deformacionais particulares, dispostas como altos e baixos gravimétricos.

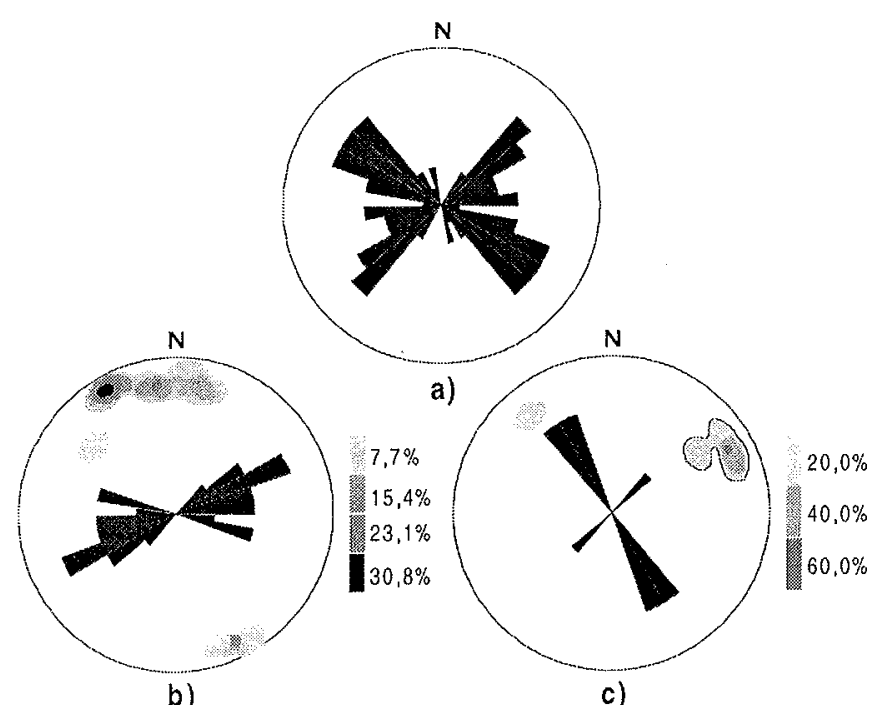

Figura 5 - a) Diagramas com fotolineamentos correspondentes a falhas com rejeito indefinido - 51 medidas; b) falhas com indicadores cinemáticos das atividades anteriores ao magmatismo, NE sinistrais - 14 medidas; c) falhas com indicadores cinemáticos das atividades posteriores ao magmatismo, $N W$ sinistrais e NE dextrais - 5 medidas
Sobre o mapa resultante da krigagem dos valores de anomalia Bouguer foram traçadas as principais feições indicativas de zonas de falhas. Tendo como objetivo o mapeamento de descontinuidades do relevo gravimétrico, foram consideradas as bruscas flexões na linhas de isovalores e as variações de gradiente. Algumas técnicas de realce foram também empregadas (análise dos resíduos da superfície de tendência de $3^{a}$ ordem, sombreamento de relevo e aplicação da segunda derivada direcional), para dar suporte às feições traçadas manualmente. No mapa gravimétrico verificam-se 3 domínios distintos, dispostos segundo a direção NE (Fig.7b). O domínio central é representado por uma faixa NE com aproximadamente $400 \mathrm{~km}$ de largura e tendência de valores mais baixos, em comparação aos domínios noroeste e sudeste

Com base no arranjo espacial dos alinhamentos identificados, observam-se grandes estruturas lineares com direção geral NE, algumas dispostas em feixe e divergindo para sudoeste. A Zona de Falha de Jacutinga, bem como sua extensão para o interior da bacia, apresenta evidente resposta gravimétrica, caracterizada pela forte orientação de dois alinhamentos segundo N50-55E, na porção central do mapa, seguindo direção aproximada à apresentada pelo baixo gravimétrico principal. O mesmo foi constatado para a Zona de Falha LancinhaCubatão, a qual apresenta continuidade por sob a bacia, e representa uma feição tectônica limítrofe entre os domínios central e sudeste. Quanto às estruturas NW, que ocorrem na região do Arco de Ponta Grossa, nota-se a superposição com relação às estruturas NE, compondo um alto local marcante, que corta o domínio central, limitado pelos alinhamentos de Guapiara e Rio Alonzo. A maioria dos elementos estruturais NW não apresenta continuidade além da estrutura limítrofe do domínio central, a noroeste.

Análise Cinemática $\mathrm{O}$ primeiro evento tectônico, pósdeposicional e anterior ao magmatismo, gerou a deformação transcorrente mais intensa nos estratos neopaleozóicos. Embora a determinação da idade deste evento seja difícil em virtude da ausência de relações elucidativas, a presença de diques não deformados em falhas NE (ou com deformação menos intensa do que a zona de falha encaixante), permite supor uma deformação anterior ao Eocretáceo. Neste caso, a deformação sinistral observada nas falhas NE, anterior ao
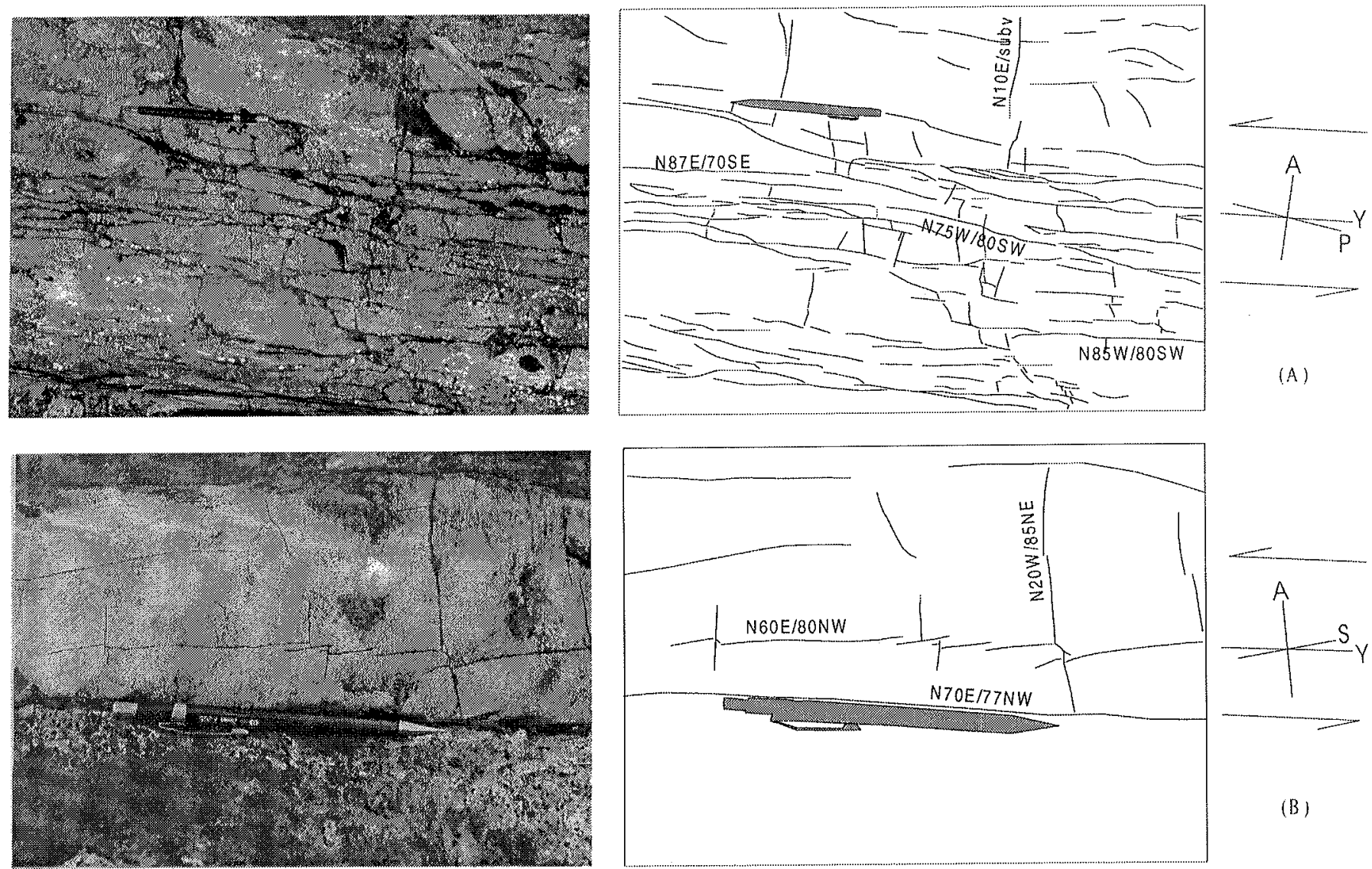

Figura 6 - Exemplos de indicadores cinemáticos em falhas de direção NE. 

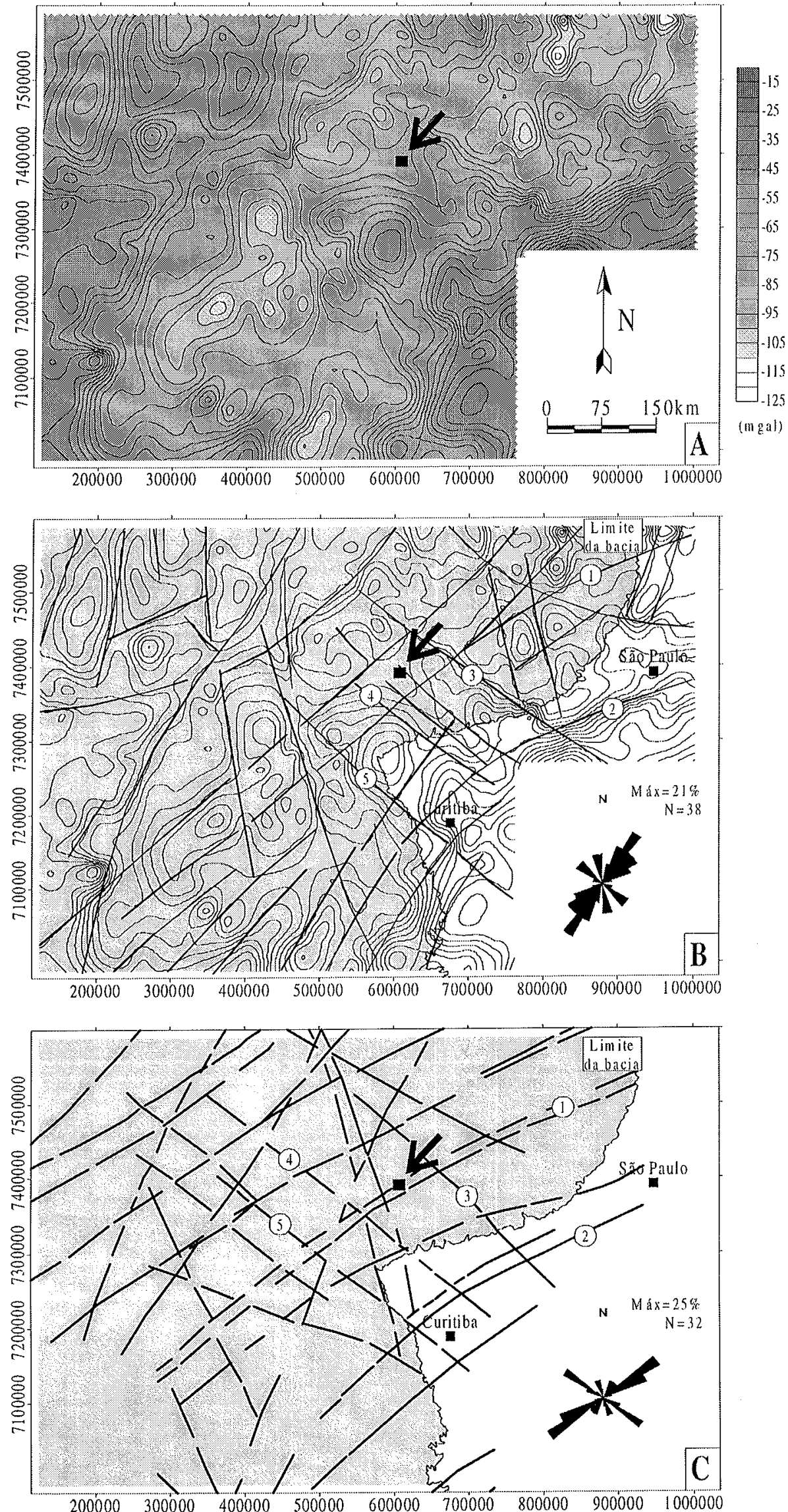

Figura 7 - A) Mapa Bouguer mostrando a compartimentação gravinétrica do embasamento encoberto (a seta indica a localização do Alto de Quatiguá); B) alinhamentos interpretados sobre o mapa Bouguer limutando blocos do entbasamento. C) Alinhanentos em superfície (segundo Soares et al. 1982 ), em parte coincidentes com os alinhamentos marcados sobre o mapa gravinétrico (Lineamentos: 1-Jacutinga; 2-Lancinha; 3-Guapiara; 4-Säo Jerônimo-Curiúva; 5Rio Alonzo). Dados gravinétricos cedidos pela Petrobrás (inédito). 
magmatismo básico, poderia estar relacionada ao reflexo da propagação de tensões compressionais intraplaca, verificada durante a Orogenia La Ventana, no limite entre o Permiano e o Triássico (Ramos 1988, Tankard et al. 1996, Milani 1997), quando ocorreu a sutura da Patagônia à América do Sul. A Orogenia La Ventana gerou uma tensão principal máxima $\left(\sigma_{1}\right)$ de sul para norte, que condicionou a reativação da Zona de Falha de Jacutinga, presente no embasamento com direção N55E (Fig.8).

O segundo evento tectônico, que afetou os diques e soleiras de diabásio, envolve uma deformação distensional, como observado em diques intrusivos nas falhas pré-existentes. As falhas geradas neste evento têm principalmente direção NW, porém com reativação local de estruturas NE ou formação de novas falhas de porte menor. Nestas últimas é difícil observar indicadores cinemáticos. Todavia, a deformação é evidenciada por deslocamentos verticais de blocos, da ordem de metros a dezenas de metros. A maior parte das falhas NE foi gerada durante o primeiro evento e a estrutura dômica formou-se numa região de cruzamento das estruturas NW e NE, durante a deformação posterior. A forma final da feição dômica resulta da composição de esforços tracionais, responsáveis pela reativação de ambas as direções, NW e $\mathrm{NE}$, como falhas principalmente distensionais, condicionadas à formação do Arco de Ponta Grossa. Na Falha de Joaquim Távora (N70E) constata-se a superposição de uma cinemática transtensional horária que afeta o diabásio intrudido ao longo da falha, com bloco alto a sudeste (Fig.9). Já na Falha de Quatiguá (N30-40E), aqui interpretada como falha normal, é clara a configuração de bloco baixo a sudeste, o que pode ser explicado pela deformação tardia que alçou o núcleo da estrutura, onde aflora o Grupo Itararé.

Em diversos locais, as ramificações internas do sistema de falhas NE dispõem-se em cunha ou em forma lenticular, onde as camadas estão arqueadas e elevadas, possivelmente relacionadas ao primeiro evento. A região estudada está inserida em uma estrutura positiva mais ampla, conforme se observa no mapa de contorno do topo da Formação Irati (Fig.10a). A feição maior alinha-se segundo a zona de falha, porém com inclinação menor da superfície de contorno para noroeste, configurando uma estrutura-em-flor positiva assimétrica. No interior desta feição, formou-se o Alto Estrutural de Quatiguá , que é condicionado por diversas falhas normais de pequena extensão. Nele, a presença de diques, soleiras e lacólitos, associados a uma deformação superposta, mascara as estruturas regionais NE. Enquanto o arqueamento regional tem gênese associada a um evento transpressional, a geometria dômica foi gerada sobre o alto pré-existente, porém durante um evento distensional superimposto.

Vale ressaltar que, ao contrário de alguns indicadores cinemáticos, existem diques NW seccionados por pequenas falhas NE, as quais mostram rejeito anti-horário da ordem de poucos metros, o que indica uma história deformacional também após o magmatismo. O registro estrutural verificado nas rochas básicas intrusivas deve compreender tanto a deformação eocretácea como episódios posteriores ao magmatismo Serra Geral, embora restritos ao Cretáceo. Esta situação foi igualmente observada no Alto de Pitanga, outra feição cuja história evolutiva pode ser correlacionada à do Alto de Quatiguá (conforme Soares 1974 e Soares et al. 1996). Segundo Ricomini (1995) as estruturas que delimitam o Anticlinal de Pitanga apresentam orientação NNW a NW e caráter inicialmente sinistral, enquanto as direções predominantes entre E-NE e W-SW são dextrais, relação coincidente com aquela encontrada no Alto de Quatiguá (Fig.5). Riccomini (1995) enfatiza ainda que esta deformação não afeta os sedimentos cenozóicos presentes na região do Alto de Pitanga.

O alto regional pré-existente na área de Quatiguá, alongado segundo N55E (Fig.10a,b), foi gerado durante a fase transpressiva inicial. A feição positiva pode ter facilitado o fluxo ígneo em direção ao cume da estrutura, durante a fase subsequente (Fig.10c).

Durante ou após o Eocretáceo definiu-se a geometria atual, que corresponde à superimposição de um pequeno "horst dômico", com rotação e colapso de blocos associados ao magmatismo, sobre a flexura compressional ampla formada no limite Permiano-Triássico. A inversão de movimentos já havia sido caracterizada por Soares (1991), que afirmou que as falhas NE apresentam geometria pós-deposicional de falha reversa de alto ângulo em relação ao contorno dos horizontes permianos, porém distensional com rejeito aparente no sentido do mergulho no Mesozóico.

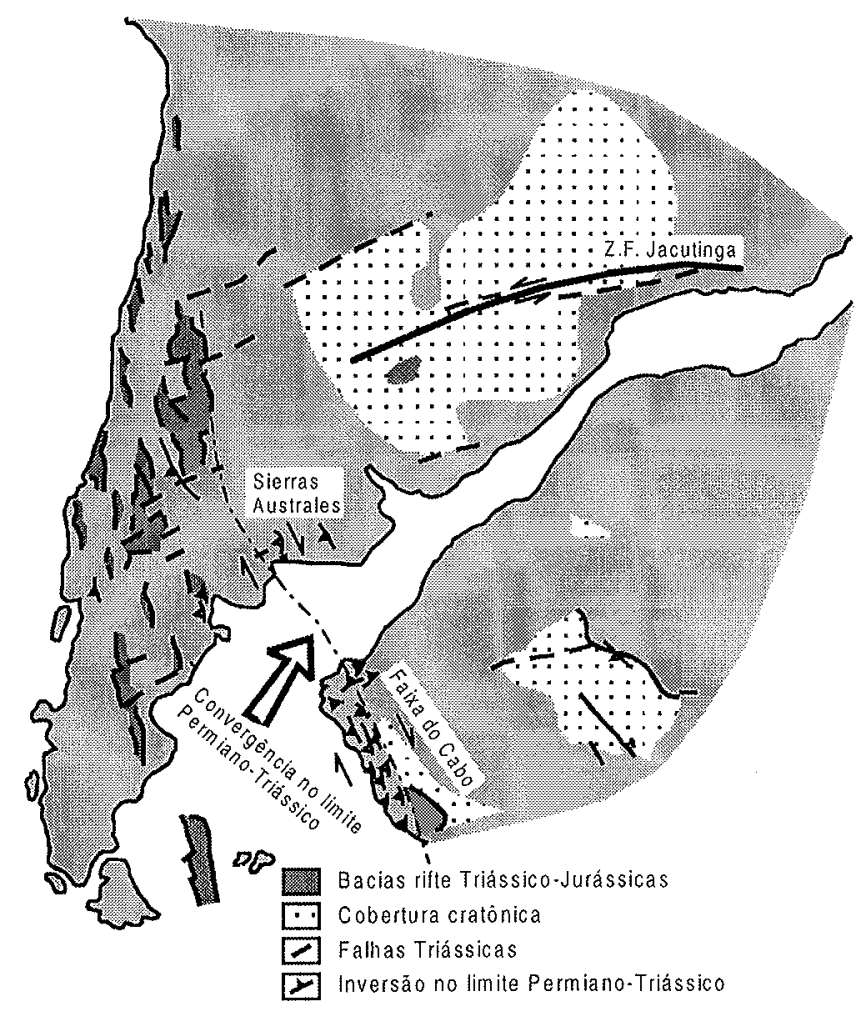

Figura 8-Reconstrução paleotectônica da porção sudoeste do Gondwana no Triássico-Eojurássico, com indicação das estrufuras de inversão relacionada. com a orogenia La Ventana no limite Permiano-Triássico (Tankard et al. 1996). Movimentos dextrais ao longo das Sierras Australes com base em Cobbold et al.199/ e na faixa do Cabo com base em Johnston (1998).

\section{IMPLICAÇÕES PARA A FORMAÇÃO DE ARMADILHAS}

PARA PETRÓLEO Segundo Milani \& Catto (1998), o potencial petrolífero da Bacia do Paraná é definido por dois sistemas petrolíferos: Ponta Grossa-Itararé (PG-I) e Irati-Rio Bonito/Pirambóia (I-RB/ P). A partir da análise das ocorrências de óleo e gás na bacia, tais autores concluiram que o potencial não descoberto do sistema PG-I estende-se por uma área ampla, apresentando potencialidade maior para descobertas de gás em armadilhas estratigráficas. Por outro lado, acumulações de óleo referentes ao sistema I-RB/P seriam possíveis em armadilhas estruturais na calha central da bacia (Milani et al. 1990), onde a Formação Irati alcançou condições de maturação, ou em regiões menos profundas, onde aquecimentos anômalos devido ao magmatismo poderiam ter promovido o craqueamento da matéria orgânica e a geração de petróleo. Artur (1998) concluiu que as áreas mais favoráveis do sistema PG-I estariam condicionadas à algumas paleoestruturas com direção NE, incluindo a faixa Pitanga-Jacutinga. Quanto ao sistema I-RB/P as melhores oportunidades ocorreriam associadas à extensão da Zona de Falha Lancinha-Cubatão, além daquelas regiöes que sofreram aquecimento anômalo devido à presença de um maior número de corpos intrusivos.

Na região do Alto de Quatiguá, afloram somente rochas da porção superior do Grupo Itararé, mas rochas do sistema PG-I estão presentes em subsuperfície, embora não se tenha dados referentes à maturação. Com relação ao sistema $I-R B / P$, afloram reservatórios da Formação Rio Bonito e rochas com alto teor em carbono orgânico da Formação Irati, que não atingiram a janela de geração de petróleo uma vez que encontram-se acima do topo da zona matura, conforme mapa apresentado em Goulart \& Jardim (1982). Embora não seja uma área favorável para o sistema I-RB/P, a região do Alto de Quatiguá constitui uma área importante para a análise deste sistema devido à boa exposição das unidades geradora e reservatório, bem como à presença de estruturas aflorantes. Informações para análise dos fatores alimentação e retenção podem ser extrapoladas para zonas mais profundas, sob os derrames basálticos da Formação Serra Geral. 


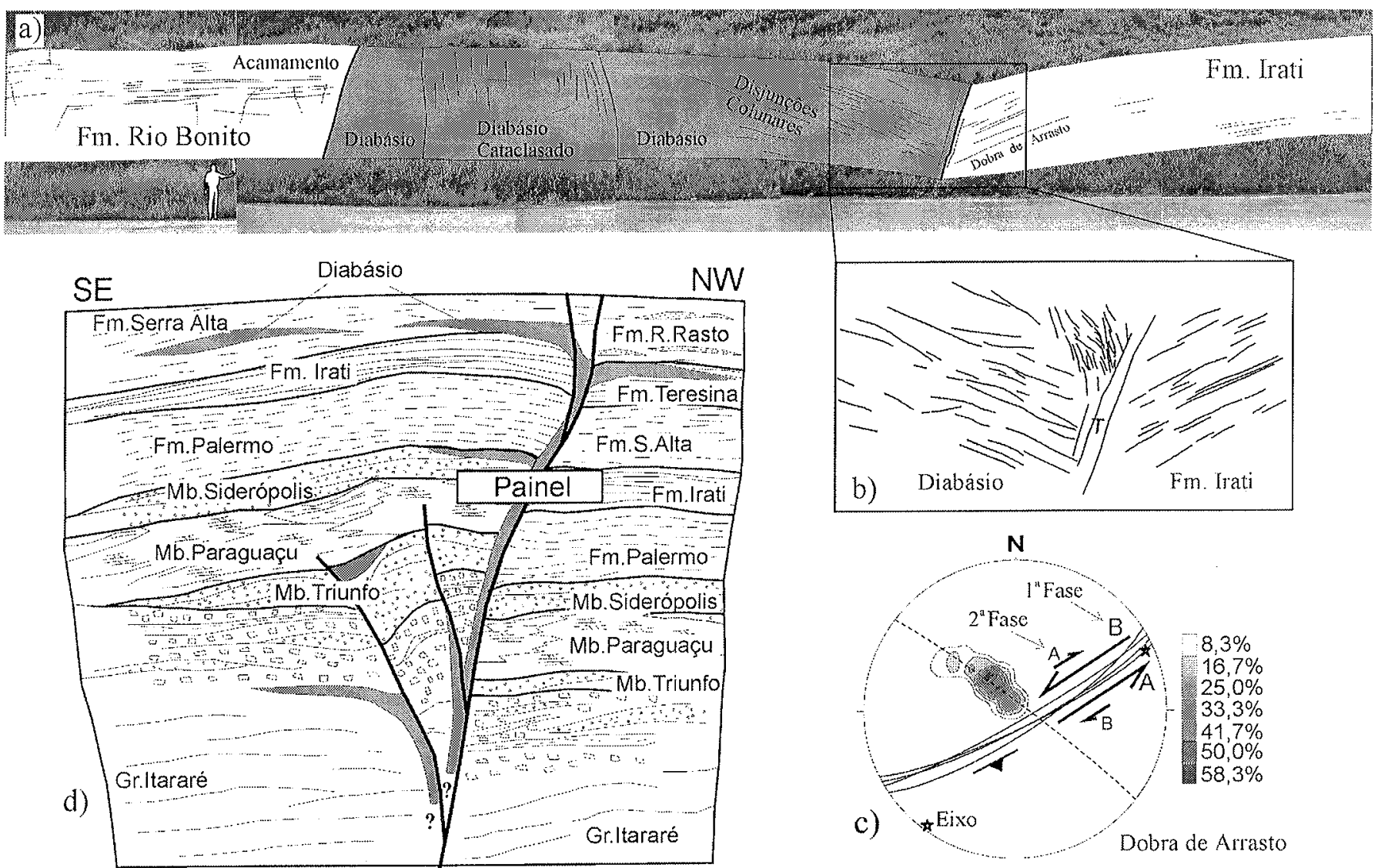

Figura 9 - a) Montagem de painel sobre afloramento na rodovia BR-153 em Joaquin Távora, trevo para Guapirama, com indicação das principais feiçöes da falha de Joaquin Távora (para localização vide figura 2); b) Detalhe da falha de Joaquin Távora; c) Diagrama com elementos estruturais reconhecidos próximo à falha de Joaquim Távora; d) seção geológica esquemática representando o modelo geológico idealizado, com indicação das unidades estratigráficas aflorantes nas proximidades da falha e localizaşäo do painel apresentado na letra a desta figura.

O modelo de acumulação considerado para o sistema I-RB/P, especificamente para os reservatórios da Formação Rio Bonito, compreende altos estruturais alongados segundo a direção NE, que teriam se formado como grandes estruturas-em-flor positivas durante o primeiro evento tectônico reconhecido na área (limite Permiano-Triássico) e, posteriormente, sofrido modificações localizadas. A migração pode ser lateral por pequenas distâncias ou vertical ao longo das falhas maiores, a partir de baixos adjacentes em direção ao alto central alinhado ao longo da zona de falha de Jacutinga. A configuração dômica pode facilitar a convergência de fluxo. As armadilhas seriam predominantemente estruturais, formadas por dobras en-echelon e horsts, onde os reservatórios litorâneos e deltaicos da Formação Rio Bonito seriam alimentados lateralmente a partir de folhelhos escuros da Formação Irati, localizados nos baixos das falhas reativadas (situação encontrada, por exemplo, na Falha de Joaquim Távora, Fig.9). Outra boa alternativa a considerar, porém de mais difícil predição, seria a presença de trapas estratigráficas ou combinadas.

As características geométricas da feição mapeada devem repetir-se ao longo da zona de falha, sugerindo que bons prospectos devam ocorrer em regiões mais profundas na calha central da bacia. A Formação Irati alcançou seu pico de geração provavelmente só no Cretáceo (Milani \& Catto 1998), o que restringe a configuração definitiva das armadilhas ao último evento de deformação. Como consequência desta deformação, horsts associados a transcorrências e blocos altos de falhas normais compõem as últimas estruturas trapeadoras, em situaç̃es onde os reservatórios estejam em condição adequada. As armadilhas preservadas da fase compressional estariam localizadas no alto central de estruturas-em-flor positivas, enquanto aquelas condicionadas às estruturas da fase distensional subsequente poderiam ser encontradas tanto no centro como nas bordas da estrutura (Fig.11).

Em síntese, a estruturação do Alto de Quatiguá é um guia exploratório importante para uma bacia pouco tectonizada, onde a

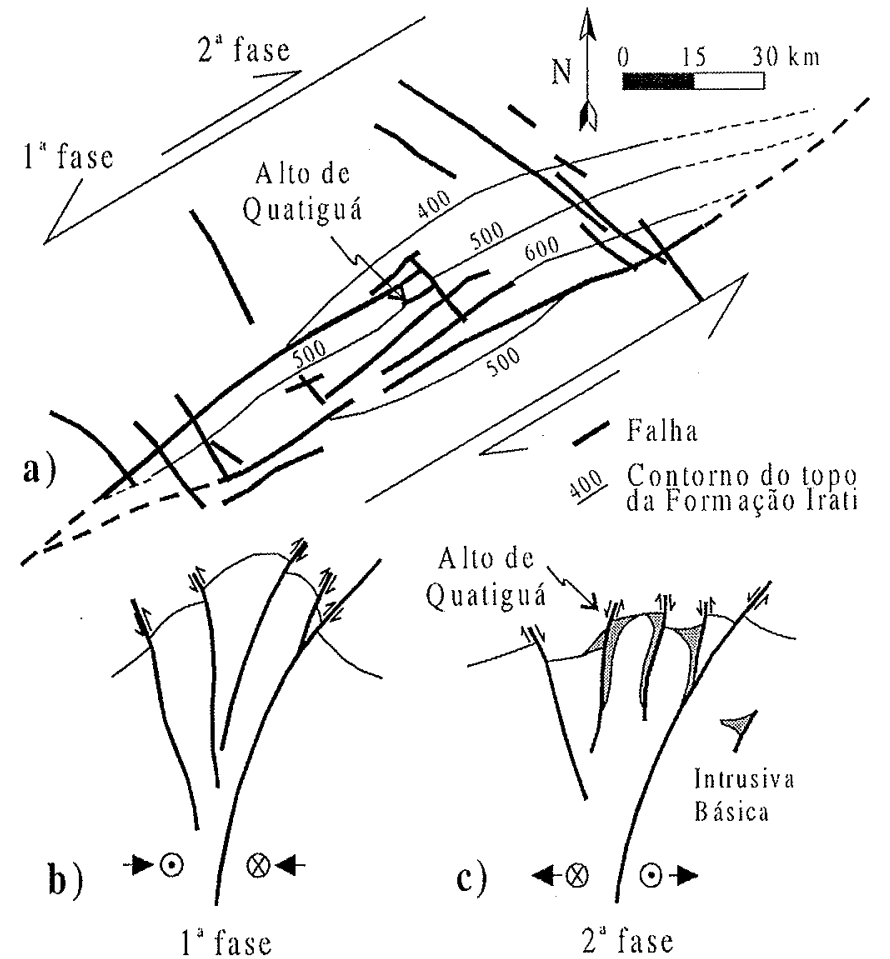

Figura 10 - Modelo esquemático da evoluçăo estrutural do Alto de Quatiguá (explicaçós no texto; mapa de contorno retirado de Lares 1991). 
deformação é localizada e associada à reativação de descontinuidades do embasamento. Embora analisado em termos do sistema I-RB/P, o modelo de estruturação pode ser aplicado na exploração de ambos os sistemas petrolíferos, ao longo dos principais lineamentos estruturais, em regiões mais profundas da bacia onde as condições de maturação sejam adequadas.

CONCLUSÕES O Alto Estrutural de Quatiguá constitui uma feição gerada pela superposição de, no mínimo, dois eventos tectônicos ocorridos a partir do final do Permiano.

1 A deformação na cobertura paleozóica foi consequêencia da reativação da Zona de Falha de Jacutinga, existente no embasamento da bacia.

2 Foram reconhecidos dois eventos importantes de tectônica deformadora, com reativação da Zona de Falha de Jacutinga. O primeiro, transpressivo e com cinemática NE anti-horária, é interpretado como derivado da propagação intraplaca de tensões compressivas durante a Orogenia La Ventana, na passagem Permiano-Triássico. O segundo, de caráter transcorrente distensivo, provavelmente horário ao longo das falhas NE, ocorreu durante e/ ou após o magmatismo Serra Geral.

3 A forma dômica representa a superposição da deformação distensiva, no segundo evento, sobre uma estruturação compressiva gerada no primeiro, em uma zona de cruzamento das direções NE e NW.

4 Ao longo da Zona de Falha de Jacutinga interpreta-se uma estrutura-em-flor positiva, de caráter regional, na qual insere-se o Alto de Quatiguá.

5 O magmatismo Serra Geral teve papel fundamental na geometria final, causando alçamentos e rotações de blocos, bem como a geração extensiva de falhas e diques de direção NW e, subordinadamente, NE.

6 As características descritas foram observadas principalmente em campo. Espera-se que estudos baseados na análise de seções sísmicas de reflexão e poços possam avaliar em subsuperfície o modelo geométrico apresentado, especialmente com relação à existência de estruturas-em-flor positivas com fallas convergentes em profundidade.

7 É possível que o registro das deformações, com relativa complexidade na cobertura, possa ser resultado de movimentos simples de blocos no embasamento, sob estados uniformes de tensões, embora recorrentes. Para verificar tais possibilidades são necessários traba- lhos complementares em outras feições dômicas conhecidas na Bacia do Paraná.

8 As relações observadas permitiram a elaboração de um modelo preliminar de acumulações de petróleo ao longo da Zona de Falha de Jacutinga. Os fatores alimentação e retenção de petróleo, definidos com base neste modelo, podem ser utilizados como critérios prospectivos em regiões mais profundas na bacia.

Agradecimentos A dois revisores anônimos da RBG pelas críticas e sugestões; ao Prof. Dr. Paulo César Soares pela troca de idéias sobre o tema; ao CNPq (processo no 520063/98-8) e à Fapesp (Processo $\mathrm{n}^{\circ}$ 98/02183-3) pelo apoio financeiro; à UFPR pelo apoio institucional e à PETROBRÁS - Petróleo Brasileiro S/A pela cessão dos dados gravimétricos.

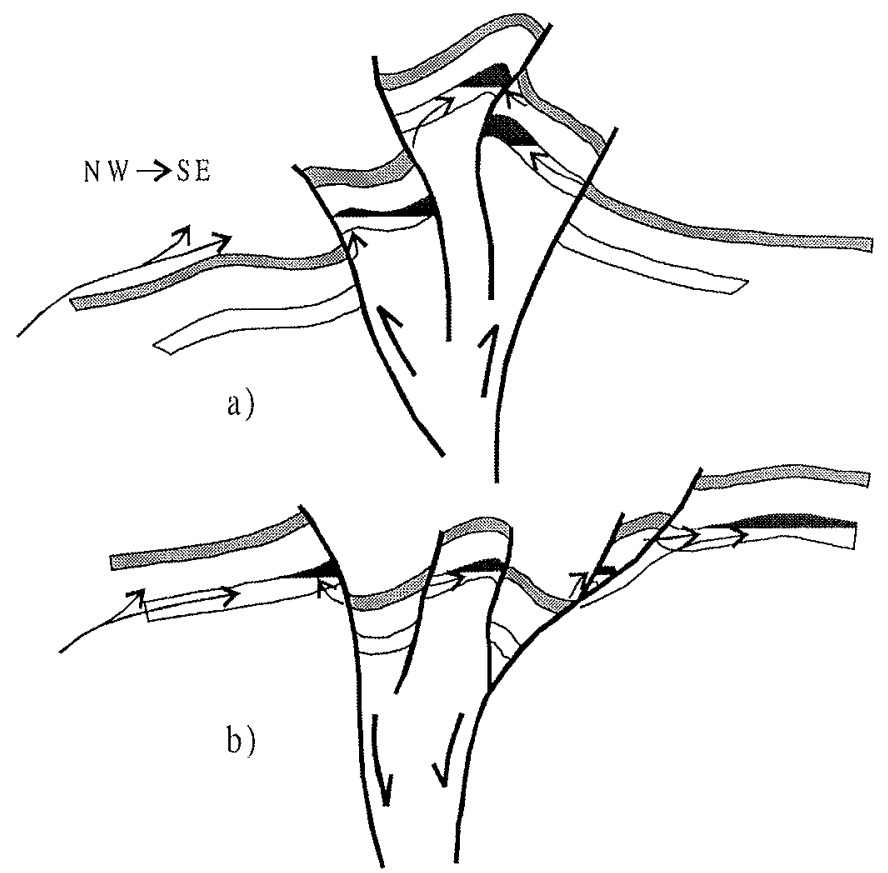

Figura /I - Modelos de formação de armadilhas estruturais para petróleo, concebidos a partir da análise estrutural do Alto de Quatiguá.

\section{Referências}

Almeida FFM. 1980. Tectônica da Bacia do Paraná no Brasil. São Paulo, Relatório Paulipetro, $187 \mathrm{p}$

Andrade S.M., Soares P.C. 1970. Geologia de Semi-Detalhe do Centro-Leste do Paraná. Relatório Petrobrás-Desul (Rel.400)

Andrade S.M. Soares PC 1971 Geologia do Centro-Leste do Estado de São Paulo. Relatório Petrobrás-Desul (Rel.407)

Artur P.C. 1998. Paleolineamentos na Bacia do Parmá: Favorabilidade para acumulaçöes de petróleo. Dissertação de Mestrado. UFPR. 202 p.

Brito Neves B.B. Fuck R.A. Cordani U.G., Thomaz Fo A. 1984. Influence of basement structures on the evolution of the major sedimentary basins of Brazil: a case of tectonic heritage. Joumal of Geodynanics, 1:495-510.

Campanha G.A., Fernandes L.A., Gimenez Filho A. 1983. Quadrículas Moji-Guaçu e Águas de Lindóia. In: Jornada Sobre a Carta Geológica do Estado de São Paulo em 1.50000 1 São Paulo, 1983. Atas, São Paulo, Pró-Minério/Secretaria da Indústria, Comércio, Ciência e Tecnologia. P.137-169.

Cava L T 1985. Potencial perspectivas para carvâo mineral do Estado do Paraú. Relatório Interno Mineropar S.A. Curitiba, $133 \mathrm{p}$

Cobbold, PR.; Gapais, D.: Rosselo, E.A. 1991. Partitioning of transpressive motions whitin a sigmoidal foldbelt: The Variscan Sierras Australes, Argentina. Journal of Structural Geology, 13:743-758

Cordani U.G., Brito Neves B.B., Fuck R.A., Porto R., Thomaz Filho A., Cunha F.M.B. 1984. Estudo preliminar de integração do Pré-Cambriano com os eventos tectônicos das bacias sedimentares brasileiras. Bolefim Ciência Técnica Petróleo, Seção Exploração de Petróleo. n. 15,70 p.

Ferreira F.J.F. 1982. Alinhamentos estruturais magnéticos da região centro-oriental da Bacia do Paraná e seu significado tectônico. São Paulo: Relatótio Paulipetro. Consórcio CESP/IPT. p. 143-166

Ferreira FI.F., Forlin M., Donatti L.M., Rostirolla S.P., Soares P.C. 1996. Assinatura Magnética de Estruturas Dômicas da Região de Fartura (SP.PR). In: Congr.Bras.Geol., 39. Salvador, SBG V.2 p. $341-343$.
Fúlfaro V.J., Saad A.R., Santos M.V., Vianna R.B. 1982. Compartimentação e evoluçāo tectônica da Bacia do Paraná. Revista Brasielira de Geociências, 12(4):590-610.

Goulart E.P., Jardim N.S. 1982. Avaliação geoquímica das formações Ponta Grossa e Irati - Bacia do Paraná. In: Paulipetro, Geologia da Bacia do Paraná: reavaliasan potencialidade e prospectividade em hidrocarbonetos. São Paulo, p.41-74.

Johnston, S.T. 1998. The kardo basin, the capefold belt and sintaxis, and the rotaded falkland islands. A comprehensive tectonic model. Journal of African Earth Sciences, $27(1 \mathrm{~A}): 120-122$

Mantovani M.S.M., Shukowsky W., Basei M.A.S., Vasconcellos A.C.B.C. 1989. Modelo gravimétrico das principais descontinuidades crustais nos terrenos pré-cambrianos
dos estados do Paraná e de Santa Catarina. Revista Brasileira de Geociências, dos estados do

Melfi A.J., Picirillo E.M., Nardy A.J.R. 1988. Geological and magmatic aspects of the Paraná Basin - an introduction. In: Piccirillo E.M., Melfi A.J. (ed) The Mesozoic Flood Volcanism of the Parana Basin: Petrogenetic and Geophysical Aspects. Instit.Astron.Geofis. Universidade de São Paulo, p. J-14

Milani E.J. 1997. Evolação Tectono-Estratigráfica da Bacia do Paraná e Seu Relacionamento com a Geodinânica Fanerozóica do Gondwana Sul-Ocidental. Tese de Doutoramento. UFRGS. 254 p. + volume de anexos

Milani E.J., Kinoshita E.M. Araújo L.M. de, Cunha P.R. da C. 1990. Bacia do Paraná: E.J., Kinoshita E.M., Araújo L.M. de, Cunha P. Reoc. Petrobrás, 4(1):21-34.

Milani E \& Catto E 1998. Petroleum Geology of the Paraná Basin, Brazil. AAPG International Conference \& Exhibition. p.442-443.

Milani E I Frana A B Schneider R.L 1994 Bacia do Paraná. Bol. Geoc. Petrobrás E.J., França A
$8(1): 69-82$.

Nagalli J.T. 1977. Projeto Siqueira Campos. Relatório Interno Nuclebrás, Curitiba-PR. Nogueira Filho J. 1988. Heranţa Tectônica na Evoluçäo Estrutural da Bacia do Paraná O Domo de Quatiguá. Relatório de Iniciação Científica, CNPq Processo 500016/887. $48 \mathrm{p}$.

Oliveira M.J.R. 1991. Análise do Comportanento da Zona de Falha Cubatão-Lancinha na Bacia do Paraní. Dissertação de Mestrado. UFOP. 144 p. 
Piccirillo E.M., Bellieni G., Cavazzini G., Comin-Chiaramonti P., Petrini R., Melfi A.J., Pinese J.P.P., Zantadeschi P., De Min A. 1990. Lower Cretaceous tholeiitic dyke swarms from the Ponta Grossa Arch (southeast Brazil): Petrology, Sr-Nd isotopes and genetic relationships with the Paraná flood volcanics. Chemical geology; 89:19 48 .

Quintas,M.C.L. 1995. O Embasamento da Bacia do Paraná: Reconstrução Geofísica de seu Arcabouco. Tese de Doutoramento. USP. 213 p.

Ramos A.N. 1970. Aspectos paleo-estruturais da Bacia do Paraná e sua influência na sedimentação. Boletim Técnico da Petrobrás, Rio de Janeiro, 13(3/4):85-93.

Ramos V. 1988. Late Proterozoic - Early Paleozoic of South America: a collisional history. Episodes, v.11, p. 168-174

Rocha-Canpos A.C., Cordani U.G., Kawashita K., Sonoki H.M., Sonoki I.K. 1988. Age of the Paraná flood volcanism. In: Piccirillo E.M., Melfi A.J. (ed) The Mesozoic Flood Volcanism of the Parana Basin: Petrogenetic and Geophysical Aspects. Instit.Astron.Geofis. Universidade de São Paulo, p.25-46.

Riccomini C. 1995. Tectomismo gerador e deformador dos depósitos sedimentares pósGondwânicos da porcāo centro-sriental do estado de São Paulo e áreas vizinhas. Tese de Livre-Docência, Universidade de São Paulo, $100 \mathrm{p}$.

Rostirolla S.P. Assine M.L. Fernandes L A. Artur PC. 1999. Origem e Evolução Tectônica do Domo de Quatiguá, Bacia do Paraná. VII SNET, Lençóis, BA, 1999. Anais... Sessão 2, pág.81-83. SBG/ABGP.

Petrobrás (inédito). Dados gravimétricos da Bacia do Paraná, cedidos pela PETROBRÁS/ NEXPAR Curitiba, Paraná, em 1994.

Schneider R.L., Muhlmann H., Tommasi E., Medeiros R.A., Daemon R., Nogueira A. 1974 Revisão estratigráfica da Bacia do Paraná. In: Congr:Bras.Geol., 28, Porto Alegre, 1974. Anais... Porto Alegre, SBG, V.1, p.41-65.

Soares P.C. 1974. Elementos estruturais da parte nordeste da Bacia do Paraná: Classificação e Gênese. In: Congr:Bras:Geol., 28, Porto Alegre. Anais... Porto Alegre, SBG. V.1, p. 107-121

Soares P.C. 1991. Tectônica Sinsedimentar Cíclica na Bacia do Paraná: Controles. Tese de Titular, Universidade Federal do Paraná. 148 p. Curitiba

Soares P.C., Cava L.T. 1982. Faciologia e Potencial Carbonífero da Formação Rio Bonito no Norte do Estado do Paraná. In: Congr:Bras.Geol. 32, Salvador. Anais Salvador, SBG, v.3, p.1120-1128

Soares P.C. Landim P.M.B., Fúlfaro V.J. 1978. Tectonic cycles and sedimentary sequences in the brazilian intracratonic basins. GSA Bulletin, v.89, p.181-191.

Soares P.C., Barcellos P.E., Csordas S.M. 1982. Análise, interpretação e integraçāo de lineamentos a partí de imagens (Radar-Landsat) e suas relações com a tectônicat
da Bacia do Paraná. São Paulo: Relatório RT-342/82, Paulipetro. Consórcio CESP/
IPT.

Soares P.C., Rostirolla S.P., Ferreira F.J.F, Stevanato R. (1996). O alto estrutural PitangaQuatiguá-Jacutinga na Bacia do Paraná: Uma Estrutura Litosférica. In: Congs. Bras: Geol., 39 Salvador 1996. Anais...Salvador, SBG. V.5 (411-414).

Tankard A.J., Uliana M.A., Welsink H.J., Ramos V.A., Turic M., Franca A.B., Milani E.J. Brito Neves B.B., Eyles N., Santa Ana H., Wiens F., Cirbian M., López Paulsen O. Germs G.J B., de Wit M., Machacha T, Miller R.M. 1996. Tectonic controls of basin evolution in southwestern Gondwana. AAPG Menoir. 62, p. 5-52

USAF 1966. Levantamento Aerofotogramétrico do Território Brasileiro, Força Aérea NorteAmerevantamento Aerofotogr

Vieira A.J., Maingué E. 1972. Geologia de semi-deralhe do centro e nordeste do Parand e centro-sul de São Paulo. Relatório Interno Petrobrás/Desul n,425, Ponta Grossa-

White R., McKenzie D. 1989. Magmatism at Rift Zones: The Generation of Volcanic Continental Margins and Flood Basalts Journal of Geophysical Research, 94(B6):7685 7729.

Zalán P.V., Wolff S., Conceiçăo J.C.J., Astolfi M.A.M., Vieira I.S., Appi V.T., Zanotto O.A 1987. Tectônica e Sedimentação da Bacia do Paraná. III Simp.Sul-Bras.Geol., v. I p. $441-473$.

Zalán P.V., Wolff S., Astolfi M.A.M., Vieira I.S., Conceição J.C.J. Appi V.T., Neto E.V.S Cerqueira J.R., Marques A., 1990. The Paraná Basin, Brazil. Tulsa: AAPG Memoi 51, p. $681-708$

Manuscrito A-1105

Recebido em 21 de julho de 1999

Revisão dos autores em 15 de março de 2000 Revisão aceita em 30 de março de 2000 